\title{
Factors Affecting Quality of Life in Patients with Pediatric Leukemia during Induction Chemotherapy.
}

\author{
Eman D. El Desouky¹, Maissa K. Noaman', Lobna M. Shalaby², Sanna Y. Shaaban², \\ Inas A. Elattar ${ }^{1}$
}

${ }^{\mathbf{1} B i o s t a t i s t i c s}$ and Cancer Epidemiology, ${ }^{2}$ Pediatric Oncology Department, National Cancer Institute, Cairo University, Egypt. ${ }^{3}$ Pediatrics Nutrition, Faculty of medicine, Ain Shams University, Egypt.

Received: April $2016 \quad$ Accepted: June 2016

\begin{abstract}
Objectives: The aim of this study is to describe quality of life (QoL), identify predictors of worse QoL and examine QoL changes from diagnosis and the end of induction chemotherapy in acute leukemia pediatric patients. Methods: A prospective study was conducted, including 105 newly diagnosed leukemic patients aged from 2 to 17 years at pediatric department, National Cancer Institute, Cairo University. Parents were interviewed to complete QoL assessment questionnaire using the PedsQL 4.0 Acute Cancer Module. Older children (more than 13 years) were interviewed using the same questionnaire version. Results: Patients had an overall score of a median 39 (range 25-64) that changed by the end of induction (median 41.7, range 0-75). Pain and hurt reported a median score of 12 (range 0-100) at diagnosis and by the end of induction, median score was 75 (range 50-100). Both scores were statistically significant being improved by therapy. Both Cognitive Problems and Perceived Physical Appearance worsen by end of induction. Girls and older children had worse QoL. Conclusions: Girls and older children had worse QoL. Cognitive Problems and Perceived Physical Appearance deteriorate by therapy. Chemotherapy regimens for childhood leukemia are lengthy with medications administered over 2.5-3.5 years, and thus future efforts should focus on longitudinal studies that describe QoL over time within individual patients.
\end{abstract}

Key words: Pediatric leukemia, quality of life, induction chemotherapy

Corresponding author: Eman D. El Desouky, e-mail: dr.emandesouky@yahoo.com

\section{Introduction}

Leukemia is the most common type of childhood cancer. It accounted for $30 \%$ of all cancers diagnosed in children younger than 15 years. $^{1}$ Within this population, acute lymphoblastic leukemia (ALL) occurred around five times more frequently than acute myeloid leukemia (AML). It accounted for approximately $78 \%$ of all childhood Leukemias, while AML accounted for about $19 \%$ of the childhood Leukemias ${ }^{2}$. Survival rates have improved dramatically over the latter course of the 20th century for most forms of childhood cancers including leukemia ${ }^{3}$.

Now that the majority of pediatric patients survive their cancer, quality-of-life measurement is progressively recognized as an important method of evaluating the effect of treatment interventions and understanding the short and long-term morbidity ${ }^{4-5}$.

Outcomes for children with leukemia have continued to improve over time, and currently, almost $80 \%$ of children with

$\begin{array}{lllll}\text { The Egyptian Journal of Community Medicine } & \text { Vol. } 35 & \text { No. } 4 & \text { October } & 2017\end{array}$


ALL are cured of their disease with primarily outpatient chemotherapy. ${ }^{6}$ For AML, the 5-year survival rate increased from less than $20 \%$ to $68 \%$ for children younger than 15 years and from less than $20 \%$ to $57 \%$ for adolescents aged 15 to 19 years ${ }^{7}$.

Because cure rates have increased, more importance has been placed on reducing toxicities of therapy, improving quality of life $(\mathrm{QoL})$ during treatment and minimizing long-term effects of therapy ${ }^{8}$.

A systematic review has examined measurement of QoL for children with ALL Most research has focused on survivorship and much less on the period during ongoing treatment ${ }^{(9)}$. Few studies have focused exclusively on acute myeloid leukemia (AML) $\mathrm{Qol}^{10}$.

Although the outlook for survival is now optimistic for children with Leukemia, facing a life threatening condition can be strongly difficult for children and their parents. Family life becomes interrupted and the child, parents and other family members are disparate with a lengthy treatment regime and possible side effects. In the initial and intermediary treatment phase, patients can experience unpleasant physical side effects such as nausea and vomiting, mucositis, fatigue, bleeding and infection ${ }^{11}$.

Recognition of the adverse effects of treatment for ALL has resulted in a growth of interest in quality of life (QOL) assessment of children. In health care, the concept of QOL, often used interchangeably with the term 'health related QOL' is generally understood as a multi-dimensional construct concerning an individual's awareness of the impact of illness and treatment on his/her health, wellbeing or functioning in relation to physical, psychological, and social aspects of life $^{12}$. QOL is now considered an important outcome measure for children with cancers not just in the long term effects but also during courses of active treatment.

The present study's objectives were to describe QoL in children with Leukemia at diagnosis, identify predictors of reduced QoL and to describe how QoL changes by the end of induction.

\section{Patients and Methods}

\section{Patients}

After IRB approval to conduct this prospective study, 105 leukemic children patients were only eligible if they were at least 2 years of age (lower limit for instrument availability) to 17 years from pediatric department at the National Cancer Institute, Cairo University were recruited in a consecutive fashion in the period from October 2013 to June 2014 with additional follow up for 3 months from the last patient recruited. An informed consent was obtained from parents of those children and an additional informed assent was obtained from children above 7 years old.

\section{Methods}

Patients were approached for participation to complete an interview based questionnaire about child QoL. Data tools were general assessment sheet and QoL questionnaire. The general assessment sheet included demographic information, socioeconomic status evaluated by $\mathrm{Al}$ Shakhs ${ }^{13}$ familial socioeconomic status scale (SES) for hospitalized patients, information on diagnosis and treatment. Anthropometric parameters, such as body weight and height were measured. Some parameters like weight for age and height for age were calculated and inferred in accordance with the Egyptian growth percentile charts. Malnutrition definition of every single parameter was done based on American Society for Parenteral and Enteral Nutrition (ASPEN) being less than 
$10^{\text {th }}$ percentile for Weight for age, height for age and less than $5^{\text {th }}$ percentile for BMI.

\section{Outcomes}

Quality of life was assessed by the 27-item PedsQL 4.0 Acute Cancer Module, which is a copyrighted material available at www.pedsql.org and a multidimensional instrument that is reliable and valid in children with cancer. The questionnaire assesses the following eight dimensions: pain and hurt, nausea, procedural anxiety, treatment anxiety, worry, cognitive problems, perceived physical appearance and communication. The cultural, linguistic validation process consists of 3 steps: forward translation, backward translation, and patient testing. In the first step, the instruments were translated from the English version to the Arabic version. It was done independently by two translators, native Arabic speakers, and bilingual in English language. The second step, the Arabic version was translated back to English version. It was done independently by two professional translators; native English speakers, and bilingual in Arabic language. In this step, in order to detect any misunderstandings, mistranslations or inaccuracies in the intermediary forward version of the questionnaire, a comparison between the backward versions with the original version was assessed. Finally, to determine whether the translation (instructions, items and response choices) was acceptable, understood the way it was supposed to, or the language used was simple and appropriate, the translated questionnaire was tested in 5 cancer families, both in children and their families. All PedsQL ${ }^{\mathrm{TM}}$ translations were conducted in close ongoing collaboration with Mapi Research Institute, Research Institute in Lyon, France and with Dr. James W. Varni in 2012.
It is available for children aged: $5-7,8-12$ and 13-18 years old; as well as for the guardians of children aged: $2-4,5-7,8-12$ and 13-18 years old. The scale has five Likert response options: never, almost never, sometimes, often and almost always. To simplify the interpretation, all Likert scales were converted to $0-100$. Higher scores indicate a higher HRQOL.

\section{Statistics}

Children with impaired QoL was defined as those with a QoL score at least two standard deviations below the age-specific population mean; these values were derived using data from a PedsQL database (14) and comparisons between poor and good Qol were analyzed with $\chi^{2}$ (chi square) test and Fisher's exact test when appropriate for categorical variables. Comparisons between the 2 groups with respect to normally distributed numeric variables were done using the t-test. Non normally distributed numeric variables were compared by Mann-Whitney test. To compare QoL score in children between diagnosis and end of induction therapy, the Wilcoxon signed rank test was used. All Data management and statistical analysis were performed using the Statistical Package for Social Sciences (SPSS) version 21. All tests of significance were two sided, and statistical significance was defined as $\mathrm{p}<0.05$.

\section{Results}

Patients' criteria: One hundred and five patients (105) were studied 60 of them were boys $(57.1 \%)$ with median age 5 years When divided by age groups, 42 (40\%) were 2-4 years, $18(17.1 \%)$ were 57 years, $15(14.3 \%)$ were $8-12$ years and $30(28.6 \%)$ were $\geq 13$ years of age. $64.8 \%$ were acute lymphocytic leukemia (ALL). The Demographic characteristics, type of disease, are presented in Table1 
PedsQol score changes: Table 2 describes the PedsQL scores initially and at the end of induction. Overall score was slightly improved from 39.4 ranged from 25 to 64.6 at diagnosis to 41.7 ranged from 0 to 75 at end of induction. Pain and hurt score was significantly improved. However, cognitive problems, perceived physical appearance were deteriorated by therapy.

Factors affecting quality of life: Eighty two patients $(78.1 \%)$ were identified to have poor quality of life. Table 3 and 4 are showing the factors in relation to Qol status in patients. Children with older age has poor quality of life as shown in Table 3 , median age was 7 years compared to 3 years in good quality of life group. Females have worse QOL as compared to male $(88.9 \%$ compared to $70 \%)$. No other factors like SES, diagnosis, weight and other nutritional related symptoms showed significant relation in this study.

\section{Discussion}

We have described QoL for 105 children with leukemia in first remission during active treatment. Our findings are concordant with others who have found that QoL scores are lower in children receiving treatment for ALL compared to children with ALL 12 months off therapy ${ }^{15}$ and lower compared to healthy children. ${ }^{16-}$ 18 These findings are also concordant with qualitative studies of children receiving treatment for ALL that have noted problems with fatigue, detrimental effects of disease and treatment on physical activities as well as difficulties with social interactions. ${ }^{19,20}$

The second objective was to describe predictors of poor QoL during treatment for leukemic patients. Our results revealed that older children and girls had worse QoL and this was concordant with others $^{18,19}$.
Our third objective was to describe how QoL changes during different phases of therapy. We found very similar QoL scores across different time of assessment for many aspects of QoL. We also found that cognitive functioning worsened over time. This finding is not intuitive because children on maintenance therapy should be integrating better into the school environment over time. Further research is warranted to determine whether this finding is replicated in other studies and if so, whether interventions could be targeted to improve cognitive functioning. Perceived physical appearance worsened over time. This finding might be due to side effect of therapy. However; further research is needed to know how to support patients to overcome this hindering concept from being active.

Our study demonstrated that pain and hurt and total score has improved by end of induction therapy. An Indonesia study also had similar findings they also found that pain and hurt, procedural anxiety and communication were better during maintenance phases of treatment compared to phases preceding maintenance. ${ }^{20}$

Although this study was a longitudinal prospective study, limitations of the sample size should be considered and further larger studies should be conducted. This study is concerned with patients in active treatment which is lacking in the published data, however; more follow up is needed to assess different phases in treatment. More information on the natural history of HRQL during all phases of treatment and survival is needed.

In conclusion, we have described QoL in children with leukemia and found that age and gender predicted QoL. Future efforts should focus on longitudinal studies that describe QoL over time within individual patients both during and after completion of therapy. 


\section{References}

1. Pritchard-Jones K, Pieters R, Reaman GH, Hjorth L, Downie P, Calaminus G, Marianne C, Wilstra N\& SteliarovaFoucher: Sustaining innovation and improvement in the treatment of childhood cancer: lessons from high-income countries 2013. The lancet oncology.

2. Siegel R, DeSantis C, Virgo K, Stein K, Mariotto A, Smith T, Cooper T, Gansler T, Lerro C, Fedewa S, Lin C, Leach C, Cannady RS, Cho H, Scoppa S, Hachey M, Kirch R, Jemal A, Ward E. Cancer treatment and survivorship statistics, 2012. CA: a cancer journal for clinicians, 62(4), 220-241.

3. SEER (Surveillance, Epidemiology and End Results), SEER Cancer Statistics Review 1973-1998. Bethesda (MD): National Cancer Institute; 1998.

4. Barr RD, Feeny D, Furlong W, Weitzman S, Torrance GW. A preference based approach to health-related quality of life for children with cancer. Int J Ped Hematol Oncol 1995;2:305-15.

5. Reaman GH, Haase GM. Quality of life research $\mathrm{n}$ childhood cancer. The time is now. Cancer 1996; 78:1330-1332.

6. Pui CH, Evans WE. Treatment of acute lymphoblastic leukemia. N Engl J Med 2006; 354:166 78.

7. Smith MA, Altekruse SF, Adamson PC, Reaman GH, Seibel NL. Declining childhood and adolescent cancer mortality. Cancer. 2014 Aug 15;120(16):2497-506.

8. Feeny D, Furlong W, Mulhern RK, Barr RD, Hudson M. A framework for assessing health related quality of life among children with cancer. Suppl Int J Cancer 1999; 12:2-9.

9. Savage E, Riordan AO, Hughes M. Quality of life in children with acute lymphoblastic leukaemia: a systematic review. Eur J Oncol Nurs 2009;13:36-48
10. Schultz KA, Chen L, Chen Z, Kawashima T, Oeffinger KC, Woods WG, Nicholson HS, Neglia JP. Chronic health conditions and health-related quality of life in survivors of childhood acute myeloid leukemia (AML): A Report from the Children's Oncology Group. Pediatric blood \& cancer. 2014 Apr; 61(4):729.

11. Viele, C. Diagnosis, treatment and nursing care of acute leukemia. Seminars in Oncology Nursing 19 (Suppl.), 2003; 98-108.

12. Varni, J., Burwinkle, T.. Health related quality of life measurement in pediatric clinical practice: an appraisal and precept for future research and application. Health and Quality of Life Outcomes, $2005 ; 3,34$.

13. AL Shakhs AA (1995):

Socioeconomic Scale for Egyptian families. Dar El Maaref El Masria, Cairo, Egypt.

14. Varni JW, Limbers CA, Burwinkle TM. Parent proxy-report of their children's health-related quality of life: an analysis of 13,878 parents' reliability and validity across age subgroups using the PedsQL 4.0 Generic Core Scales. Health Qual Life Outcomes 2007;5:2

15. Meeske K, Katz ER, Palmer SN, Burwinkle T, Varni JW. Parent proxyreported health-related quality of life and fatigue in pediatric patients diagnosed with brain tumors and acute lymphoblastic leukemia. Cancer 2004;101:2116-25.

16. Reinfjell T, Lofstad GE, Veenstra M, Vikan A, Diseth TH. Health-related quality of life and intellectual functioning in children in remission from acute lymphoblastic leukaemia. Acta Paediatr 2007;96:1280-5.

17. Shankar S, Robison L, Jenney ME, Rockwood TH, Wu E, Feusner J, Friedman D, Kane RL, Bhatia S. Health-related quality of life in young survivors of childhood cancer using the Minneapolis- 
Manchester Quality of Life-Youth Form Pediatrics 2005;115:435-42.

18. Waters EB, Wake MA, Hesketh KD, Ashley DM, Smibert E. Health-related quality of life of children with acute lymphoblastic leukaemia: comparisons and correlations between parent and clinician reports. Int J Cancer 2003;103:514-8.

19. Earle EA, Eiser C. Children's behavior following diagnosis of acute lymphoblastic leukaemia: a qualitative longitudinal study. Clin Child Psychol Psychiatry 2007;12: 281-93.

20. Sitaresmi MN, Mostert S, Gundy CM, Sutaryo S, Veerman AJ. Health related quality of life assessment in Indonesian childhood acute lymphoblastic leukemia. Health Qual Life Outcomes 2008;6:96. 
Eman D. El Desouky, et al Factors affecting Quality of life in patients with pediatric leukemia 21

Table (1): Demographic characteristics and type of disease in studied patients $(\mathbf{n}=\mathbf{1 0 5})$.

\begin{tabular}{|l|l|l|l|}
\hline \multicolumn{2}{|c|}{} & Number & Percent \\
\hline Age (yrs.) & Median (range) & $5(2-17)$ & \\
\hline \multirow{4}{*}{ Age groups } & $2-4$ & 42 & 40.0 \\
\cline { 2 - 4 } & $5-7$ & 18 & 17.1 \\
\cline { 2 - 4 } & $8-12$ & 15 & 14.3 \\
\cline { 2 - 4 } & $13-18$ & 30 & 28.6 \\
\hline \multirow{3}{*}{ Gender } & Male & 60 & 57.1 \\
\cline { 2 - 4 } & Female & 45 & 42.9 \\
\cline { 2 - 4 } & M/F Ratio & $1.3 / 1$ & 64.8 \\
\hline \multirow{3}{*}{ Residence } & ALL & 68 & 35.2 \\
\cline { 2 - 4 } & AML & 37 & 54.7 \\
\cline { 2 - 4 } & Urban & 48 & \\
\cline { 2 - 4 } & Rural & 57 & \\
\hline
\end{tabular}

ALL: Acute Lymphoblastic Leukemia, AML: Acute Myeloplastic Leukemia

Table (2): Summary scores of pedsQol at diagnosis and at the end of induction.

\begin{tabular}{|c|c|c|c|c|c|c|c|}
\hline & \multicolumn{3}{|c|}{ At diagnosis } & \multicolumn{3}{|c|}{ End of induction } & \multirow[b]{2}{*}{ p value } \\
\hline Average score of & Median & Min. & Max. & Median & Min. & Max. & \\
\hline Pain and hurt & 12.5 & 0 & 100 & 75 & 50 & 100 & $<0.001$ \\
\hline Nausea problems & 43.75 & 0 & 87.5 & 43.8 & 0 & 81.3 & 0.252 \\
\hline Procedural anxiety & 0 & 0 & 58.3 & 0 & 0 & 58.3 & 0.495 \\
\hline Treatment anxiety & 50 & 0 & 100 & 50 & 0 & 100 & 0.864 \\
\hline Worry & 16.7 & 0 & 50 & 16.7 & 0 & 50 & 0.481 \\
\hline Cognitive Problems & 56.3 & 10 & 100 & 50 & 0 & 100 & $<0.001$ \\
\hline Perceived Physical Appearance & 41.7 & 8.3 & 66.7 & 25 & 0 & 66.7 & $<0.001$ \\
\hline Communication & 66.7 & 41.7 & 100 & 75 & 0 & 100 & 0.902 \\
\hline Total Score & 39.4 & 25 & 64.6 & 41.7 & 0 & 75.0 & $<0.001$ \\
\hline
\end{tabular}


Table (3): Demographic characteristics, type of disease and laboratory parameters in children with poor and good Qol.

\begin{tabular}{|c|c|c|c|c|c|c|}
\hline & & \multicolumn{4}{|c|}{ HRQOL } & \multirow[b]{3}{*}{ P value } \\
\hline & & \multicolumn{2}{|c|}{ Poor $(n=82)$} & \multicolumn{2}{|c|}{ Good $(n=23)$} & \\
\hline & & $\mathbf{N}$ & $\%$ & $\mathbf{N}$ & $\%$ & \\
\hline Age (years) & Median(range) & \multicolumn{2}{|c|}{$7(1.8-17)$} & \multicolumn{2}{|c|}{$3(2.0-17.0)$} & 0.001 \\
\hline \multirow{2}{*}{ Gender } & Male & 42 & 70.0 & 18 & 30.0 & \multirow{2}{*}{0.021} \\
\hline & Female & 40 & 88.9 & 5 & 11.1 & \\
\hline \multirow{2}{*}{ SES } & $\leq$ Average & 44 & 80.0 & 11 & 20.0 & \multirow{2}{*}{0.621} \\
\hline & $>$ Average & 38 & 76.0 & 12 & 24.0 & \\
\hline \multirow{2}{*}{ Diagnosis } & ALL & 54 & 79.4 & 14 & 20.6 & \multirow{2}{*}{0.658} \\
\hline & AML & 28 & 75.7 & 9 & 24.3 & \\
\hline $\mathrm{Hg}$ (mg/dl) & Mean \pm SD & \multicolumn{2}{|c|}{$8.9 \pm 1.5$} & \multicolumn{2}{|c|}{$9.3 \pm 1.5$} & 0.306 \\
\hline Albumin (g/dl) & Mean \pm SD & \multicolumn{2}{|c|}{$3.5 \pm 0.5$} & \multicolumn{2}{|c|}{$3.6 \pm 0.5$} & 0.776 \\
\hline Creatinine(mg/dl) & Mean \pm SD & \multicolumn{2}{|c|}{$0.4 \pm 0.2$} & \multicolumn{2}{|c|}{$0.4 \pm 0.2$} & 0.744 \\
\hline WBCs $(10)^{3}$ & Median (range) & \multicolumn{2}{|c|}{$13.1(0.9-80.0)$} & \multicolumn{2}{|c|}{$11.8(1.2-81.4)$} & 0.951 \\
\hline Urea (mg/dl) & Median (range) & \multicolumn{2}{|c|}{$21(6-90)$} & \multicolumn{2}{|c|}{$18(3-105)$} & 0.148 \\
\hline
\end{tabular}

SES: Socio Economic Status 
Table (4): Anthropometry and nutrition related symptoms in children with poor and good Qol

\begin{tabular}{|c|c|c|c|c|c|c|}
\hline & & \multicolumn{4}{|c|}{ HRQOL } & \multirow[b]{3}{*}{ P value } \\
\hline & & \multicolumn{2}{|c|}{ Poor $(n=82)$} & \multicolumn{2}{|c|}{$\operatorname{Good}(n=23)$} & \\
\hline & & $\mathbf{N}$ & $\%$ & $\mathbf{N}$ & $\%$ & \\
\hline \multirow{2}{*}{ Weight for age } & $\leq 10^{\text {th }}$ percentile & 30 & 75.0 & 10 & 25.0 & \multirow{2}{*}{0.547} \\
\hline & $>10^{\text {th }}$ percentile & 52 & 80.0 & 13 & 20.0 & \\
\hline \multirow{2}{*}{ Height for age } & $\leq 10^{\text {th }}$ percentile & 27 & 81.8 & 6 & 18.2 & \multirow{2}{*}{0.532} \\
\hline & $>10^{\text {th }}$ percentile & 55 & 76.4 & 17 & 23.6 & \\
\hline \multirow{2}{*}{ BMI for age } & $\leq 5^{\text {th }}$ percentile & 27 & 75.0 & 9 & 25.0 & \multirow{2}{*}{0.580} \\
\hline & $>5^{\text {th }}$ percentile & 55 & 79.7 & 14 & 20.3 & \\
\hline \multirow{2}{*}{$\begin{array}{l}\text { Weight loss } \\
\text { during induction }\end{array}$} & No & 53 & 79.1 & 14 & 20.9 & \multirow{2}{*}{0.741} \\
\hline & Yes & 29 & 76.3 & 9 & 23.7 & \\
\hline \multirow{2}{*}{ Vomiting } & No & 12 & 92.3 & 1 & 7.7 & \multirow{2}{*}{0.186} \\
\hline & Yes & 70 & 76.1 & 22 & 23.9 & \\
\hline \multirow{2}{*}{ Diarrhea } & No & 50 & 75.8 & 16 & 24.2 & \multirow{2}{*}{0.451} \\
\hline & Yes & 32 & 82.1 & 7 & 17.9 & \\
\hline \multirow{2}{*}{ Nausea } & No & 31 & 75.6 & 10 & 24.4 & \multirow{2}{*}{0.622} \\
\hline & Yes & 51 & 79.7 & 13 & 20.3 & \\
\hline \multirow{2}{*}{ Constipation } & No & 70 & 79.5 & 18 & 20.5 & \multirow{2}{*}{0.414} \\
\hline & Yes & 12 & 70.6 & 5 & 29.4 & \\
\hline \multirow{2}{*}{ Dysphagia } & No & 53 & 73.6 & 19 & 26.4 & \multirow{2}{*}{0.101} \\
\hline & Yes & 29 & 87.9 & 4 & 12.1 & \\
\hline \multirow{2}{*}{ Poor appetite } & No & 28 & 77.8 & 8 & 22.2 & \multirow{2}{*}{0.955} \\
\hline & Yes & 54 & 78.3 & 15 & 21.7 & \\
\hline \multirow{2}{*}{ Mucositis } & No & 24 & 82.8 & 5 & 17.2 & \multirow{2}{*}{0.475} \\
\hline & Yes & 58 & 76.3 & 18 & 23.7 & \\
\hline
\end{tabular}

